\title{
EDITORIAL
}

\section{UM CONVITE À HISTÓRIA DAS CIÊNCIAS DA LINGUAGEM}

Marli Quadros Leite [https://orid.org/0000-0002-8417-0140]

Universidade de São Paulo, São Paulo, SP, Brasil

Maria Inês Batista Campos [htrp://orcid.org/0000-0003-0004-9923]

Universidade de São Paulo, São Paulo, SP, Brasil

\section{Considerações iniciais}

As pesquisas que se mostram neste número de Linha D'Água resultam de um esforço que temos feito para divulgar os trabalhos realizados na esfera da História das Ideias Linguisticas (HIL), alinhados com a proposta teórica oriunda da França, elaborada por Sylvain Auroux. ${ }^{1}$ Como aqui e alhures as pesquisas resultam de um caldo do que as teorias oferecem de melhor para a resolução dos problemas encontrados pelos pesquisadores durante seu fazer científico, essa teoria aparece em conexão com outras para que as pesquisas voltadas ao estudo histórico dos temas concernentes às ciências da linguagem alcancem seus objetivos.

S. Auroux é tanto filósofo-linguista quanto linguista-filósofo, primeiro, porque suas reflexões filosóficas sempre se fazem com base na relação da língua com a linguagem e dessas com com o mundo, tendo como centro o homem, e as representações que ele faz da realidade; segundo, porque seu olhar sobre a língua, para

Para conhecer S. Auroux, leia-se (CHEVALIER, 2014) e (FISHER, 2014). 
Linha D'Água (Online), São Paulo, v. 32, n. 1, p. 1-22, jan.-abril 2019

explicar sua essência e prática resulta de um saber filosófico, o que organizou seu conhecimento e o levou ao estudo e investigação dos temas linguísticos. Essa história dá indicações para entendermos o porquê da opção de Auroux por denominar seu fazer científico como "bistória das ideias", e não história das teorias linguísticas. Vale lembrar que o centro de pesquisa criado em 1984, por Jean-Claude Chevalier (CHEVALIER, 2014) e renovado em 1992, por Auroux, apoiado no Centre National de la Recherche Scientifique (CNRS), foi, e é até hoje, denominado Laboratoire d'Histoire et des Théories Linguistiques, embora a revista científica a ele relacionada, criada em 1979, não tenha no título o termo "teoria", mas "epistemologia", Histoire Épistémologie Langage (HEL). Esse título já alarga o horizonte da pesquisa praticada pelo grupo de investigadores franceses, porque suscita libertação da pesquisa relativamente ao círculo de teorias linguísticas.

Essa história, contudo, não para nesse ponto, pois, algum tempo depois de tais denominações terem sido consolidadas, os pesquisadores ligados a Auroux, e ele próprio, entenderam que a melhor denominação para o trabalho científico que praticavam era anterior, mais profundo e amplo do que diziam os termos "teoria" e "epistemologia”, esse termo é "ideia”. (Cf. COLOMBAT; FOURNIER; PUECH, 2017). Por isso, talvez, a coleção que resultou de pesquisa muito significativa para o grupo foi intitulada Histoire des idées linguistiques (1989, 1992, 2000). Essa expressão, daí em diante, passou a designar a teoria, a disciplina e as pesquisas resultantes do fazer do grupo de pesquisadores que têm os textos de Sylvain Auroux como guia para seus trabalhos.

Alguns dos textos desse número são representantes de tal orientação, outros, estão relacionados à Historiografia da Linguística, teoria que tem servido de suporte a grande parte das pesquisas históricas brasileiras, conforme expõe Leite (2019). Os leitores interessados em exposição pormenorizada sobre como tais teorias se aproximam e se distanciam poderão consultar a referida obra.

\section{Ilustração de uma análise fundada em princípios da HIL}

As ideias perpassam o tempo e não se prendem a cronologias, nem a terminologias nem a teorias. Elas, porém, habitam e marcam teorias, seja porque surgem por meio 
Linha D'Água (Online), São Paulo, v. 32, n. 1, p. 1-22, jan.-abril 2019

de terminologias novas criadas a cada tempo, para envelopar ideias apenas "renovadas", ou levemente modificadas, seja porque possibilitam o surgimento de ideias novas que, por sua vez, estruturam novas teorias, sendo que essas, inescapavelmente, abrigarão em seu bojo saberes linguísticos construídos na longa duração do tempo. Isso é apreensível, por exemplo, pelo apelo que os trabalhos linguísticos têm de fazer ou à terminologia tradicional (nome, substantivo, verbo, conjunção etc.), ou, de algum modo, a aspectos de seus conceitos. Algo parecido ocorre até quando uma terminologia é desprezada e os conceitos modificados, mas terminam aparecendo sob outros rótulos (como por exemplo, sintagma nominal e núcleo, que substituem nome ou substantivo), situação que não evita que o uso de alguns (ou os) fundamentos do que estruturou a ciência gramatical, os quais insistem em permanecer.

Ao nos perguntarmos, entretanto, se o conhecimento sobre as línguas e a linguagem, nesse caso, continua "o mesmo", a resposta é um sonoro "não", pois o conhecimento é sempre "outro", no curso do tempo. O conhecimento linguístico, gramatical, progride sempre, os conceitos entram em novos sistemas científicos, embora a sua base seja sólida e esteja presente na estruturação de novos conhecimentos, como uma espécie de "pano de fundo" sobre o qual novos saberes se acomodam, ou, para usar de outra metáfora, são conhecimentos que constituem uma espécie de "espinha dorsal", a servir de suporte às inovações. Esse tema é abordado por Sylvain Auroux, quando, ao tratar da constituição do que se pode conceber como uma gramática e explicar como se configura o instrumento linguístico denominado gramática, discorre também sobre como se deve entender a relação existente entre terminologia e conceitos que constituem a gramática:

Si l'on se place à la Renaissance et au début des grammaires françaises, la réponse est assez facile. Dans une grammaire, on trouve des termes théoriques comme « verbe », adjective », " participe passé», « imparfait », etc. Ces termes sont en général introduits par des définitions, lesquelles sont parfois simplement reprises à la tradition. Il n'est pas sûr qu'une définition abstraite soit suffisante pour identifier les items linguistiques. À ma connaissance, il n'existe pas de grammaire qui ne comporte aussi des listes (closes ou non) d'éléments classés sous ces termes théoriques (axe paradigmatique). Elles fournissent donc des définitions ostensives (" un substantive, c'est un mot comme 'montagne'»). On peut considérer que ces termes théoriques sont les concepts essentiels de la linguistique. Il convient 
toutefois d'admettre qu'un concept - tel qu'accessible à l'historien - n'est pas une représentation univoque attachée à un élément terminologique. C'est au minimum un triplet, composé : i) d'une nomenclature (le/les «nom(s)»du concept; ii) d'une (ou plusieurs) définition(s); iii) d'une (ou plusieurs) liste(s) d'éléments linguistiques. De fait, il convient de transformer le triplet en un quadruplet en lui rajoutant les textes de référence et leurs dates. Dans ces conditions, il est quasiment inconcevable de rencontrer quelque chose comme une identité transhistorique totale d'un concept; un concept évolue toujours au cours de l'histoire (sans compter les variantes que l'on rencontre au même point de la chronologie). (AUROUX: 2012, p. 31).

Se nós nos posicionarmos no Renascimento e no começo da produção de gramáticas francesas, a resposta é bem fácil. Em uma gramática encontramos termos teóricos, como 'verbo', 'adjetivos', 'particípio passado', 'imperfeito' etc. Esses termos são, em geral introduzidos por definições que, às vezes, são simplesmente retomados da tradição. Não é certo que uma definição abstrata seja suficiente para identificar os itens linguísticos. Pelo que sei, não existe gramática que comporte também listas (fechadas ou não) de elementos classificados sob esses termos teóricos (eixo paradigmático). Elas fornecem, então, definições ostensivas (um substantivo é uma palavra como 'montanha'). Podemos considerar que esses termos teóricos são termos essenciais da linguística. Convém, todavia, admitir que um conceito - tal como acessível ao historiador - não é uma representação unívoca ligada a um elemento terminológico. É no mínimo uma tríade composta de: i) de uma nomenclatura (o/os 'nome(s)' do conceito); ii) de uma (ou muitas) definição(ões); iii) de uma (ou muitas) lista(s) de elemento(s) linguísticos. Com efeito, convém transformar a tríade em uma quadra, ajuntando-lhe os textos de referência e suas datas. Nessas condições, é quase inconcebível encontrar alguma coisa como uma identidade trans-bistórica total de um conceito: um conceito evolui sempre no curso da história (sem contar as variantes que se encontram no mesmo ponto de uma cronologia). (AUROUX: 2012, p. 31). Tradução e grifos nossos.

A complexidade dessa questão revela que não é tarefa simples nem fácil tratar das ideias linguísticas, já que a função e o objetivo do pesquisador são, essencialmente, produzir conhecimento novo, ou investigar como e porque, em pontos da história, o conhecimento muda. Isto é, ou se produz ou se revela uma inovação, mas não se "descobre”. 
Auroux (2012, p. 39), acionado por sua expertise filosófica explica que "no domínio da história das ciências, distinguimos a inovação, que consiste na aparição de alguma coisa nova, da invenção que é, simplesmente, o estatuto adquirido por uma inovação reconhecida. No campo da teoria gramatical as invençôes são extremamente raras, pois consistem na formulação de uma teoria a respeito de um fenômeno não descrito. Auroux (2012, p. 41) ilustra essa ideia recorrendo à teoria do tempo de Beauzée (1717-1789), pois esse filósofo e gramático iluminista francês vislumbrou marcos temporais, ou eixos, de anterioridade, simultaneidade e posterioridade pelos quais definiu o tempo verbal francês e, também, criou o método usado para explicar o tempo referido pela forma verbal que revela o acontecimento de um evento, por projeção sobre um ou alguns desses eixos. Disse Beauzée:

II faut considérer dans les tems: 1) une relation d'existence á un terme de comparaison, 2) le terme méme de comparaison. C'est en vertu de la relation genérale d'existence qu'un tems est présent, prétérit ou futur, selon qu'il exprime la simultanéité, l'antériorité ou la postériorité d'existence; c'est par cette maniere d'envisager le terme, ou sous un point de vue general et indéfini, ou sous un point de vue spécial et determiné, que ce tems est indéfini, ou défini, et c'est par la position detérminée qu'un tems défini est actuel, antérieur ou postérieur, selon que le terme a lui-méme l'un de ees rapports au moment de l'acte de parole (BEAUZEE : 1765, p. 99, apud AUROUX : 1986, p. 291).

É preciso considerar no tempo: 1) uma relação de existência com um termo de comparação, 2) o mesmo termo de comparação. É em virtude da relação geral de existência que um tempo é presente, passado ou futuro, segundo exprime a simultaneidade, a anterioridade ou a posterioridade da existência; por esse modo de considerar o tempo, de um ponto de vista geral e indefinido, ou de um ponto de vista especial e definido, que esse tempo é indefinido, ou definido, e é pela posição determinada que um tempo definido é atual, anterior ou posterior, dependendo se o tempo tem uma dessas relações no momento do ato da fala. (BEAUZÉE: 1765, p. 99, apud AUROUX: 1986, p. 291). Traduzimos.

Essa teoria e metodologia de tratamento do tempo, gerou a teoria do sistema verbal francês e consistiu uma inovação, tanto porque o autor disse algo que ninguém havia dito, embora o fenômeno estivesse latente nas formas e expressões 
Linha D'Água (Online), São Paulo, v. 32, n. 1, p. 1-22, jan.-abril 2019

verbais, quanto porque foi uma teoria reconhecida e aceita pelos contemporâneos do filósofo, especialistas em análise da linguagem e da língua, os cientistas da linguagem de sua época, ou, em outros termos ainda, por seu grupo de especialidade. Todos se valeram dessa teoria, que passou a ser referida como "a teoria do sistema verbal de Beauzée".

É importante lembrar que tal teoria, aplicada em muitas nas gramáticas filosóficas, ${ }^{2}$ aparece em outro tempo e em contexto científico diferente, também aplicado ao estudo da língua francesa, por Benveniste (1988 [1966]), em texto intitulado “As relações de tempo no verbo francês", publicado em 1959, no Bulletin de la Societé de linguistique (LIV, fascículo 1. Nesse texto, contudo, o linguista francês não faz nenhuma referência a Beauzée. Evidentemente, a descrição dos dois autores não é a mesma e não faz parte do mesmo sistema científico, porque, dentre muitos outros fatores que não vêm ao caso no momento, de um lado, Beauzée objetivou descrever o verbo a partir do ponto de vista gramatical e, de outro, Benveniste buscou explicar o discurso, a enunciação. A plataforma teórica de ambos é muito diferente, mas é perceptível que o linguista francês contemporâneo, opera com a ideia da teoria do tempo que, sem dúvida, é a do iluminista. No horizonte de retrospeç̧ão de ambos os estudiosos da linguagem, quanto à reflexão sobre o tempo, parece haver as reflexões de Santo Agostinho, que podem ser lidas no livro XI, intitulado, "Questões de tempo", da obra Confissões, em que o filósofo afirma que o único tempo que existe é o presente, pois o passado "já foi” e o futuro ainda não é". Benveniste não se refere a Santo Agostinho, mas esse filósofo é referido por Beauzée em vários verbetes de l'Enciclopédie.

A reflexão de Beauzée, contudo, não repete a de Santo Agostinho, nem tem o mesmo propósito dela, pois esse filósofo quis dizer o que o tempo é e aquele quis entender como se diz o tempo. Esta passagem das Confissões de Santo Agostinho, não deixa dúvidas sobre o seu propósito:

2 Por exemplo, no universo dos estudos da língua portuguesa, no Brasil, Francisco Sotero dos Reis, em sua Grammatica portugueza, accommodada aos principios geraes da palavra, seguidos de immediata applicação prática, de 1866, no Brasil, estado do Maranhão, recorreu a essa teoria para descrever o tempo verbal português. 
Linha D'Água (Online), São Paulo, v. 32, n. 1, p. 1-22, jan.-abril 2019

XIV. 17. Não houve, pois, tempo algum em que não tivesses feito alguma coisa, porque tinhas feito o próprio tempo. E nenhuns tempos te são co-eternos, porque tu permaneces o mesmo; ora, se os tempos permanecessem os mesmos, não seriam tempos. Que é, pois, o tempo? Quem o poderá explicar facilmente e com brevidade? Quem poderá apreendê-lo, mesmo com o pensamento, para proferir uma palavra acerca dele? Que realidade mais familiar e conhecida do que o tempo evocamos na nossa conversação? E quando falamos dele, sem dúvida compreendemos, e também compreendemos, quando ouvimos alguém falar dele. O que é, pois, o tempo? Se ninguém mo pergunta, sei o que é; mas se quero explicá-lo a quem mo pergunta, não sei: no entanto, digo com segurança que sei que, se nada passasse, não existiria o tempo passado, e, se nada adviesse, não existiria o tempo futuro, e, se nada existisse, não existiria o tempo presente. De que modo existem, pois, esses dois tempos, o passado e o futuro, uma vez que, por um lado, o passado já não existe, por outro, o futuro ainda não existe? Quanto ao presente, se fosse sempre presente, e não passasse a passado, já não seria tempo, mas eternidade. Logo, se o presente, para ser tempo, só passa a existir porque se torna passado, como é que dizemos que existe também este, cuja causa de existir é aquela porque não existirá, ou seja, não podemos dizer com verdade que o tempo existe senão porque ele tende para o não existir? (Sto. Agostinho, Confissões XI, XIV, 17) Grifamos.

O interesse de Beauzée é gramatical e seu objetivo é descrever as expressões linguísticas verbais referentes ao tempo, a fim de explicar como elas "representam" o tempo. A definição de Beuazée para o tempo tem suporte direto em definição oriunda, como ele próprio declara, na astronomia física de Galmaches (1672$1756)^{3}$ de quem vem a ideia do tempo como "existência", pois que a definição do astrônomo é a de que "le tems est la succession même attachée à l'existence de la créature" [o tempo é a sucessão ligada à existência da criatura]. É essa noção de existência pela sucessão que estrutura a ideia de tempo do iluminista e que o faz refletir sobre como as expressões verbais (não somente as formas verbais simples) representam a "sucessão da existência". Se o ponto de partida foi a sucessão, ele reconheceu que "le tems devient à son tour la mesure de l'existence successive" [o tempo se torna, a seu turno, a medida de existência sucessiva”]. De certo modo, contudo, é forçoso

3 Beauzée (16:97) cita o Art. I. Notion générale des tems, do livro Astronomie physique (1740) de autoria do astrônomo Etienned de Gamaches. 
Linha D’Água (Online), São Paulo, v. 32, n. 1, p. 1-22, jan.-abril 2019

reconhecer nesse pensamento a reflexão de Santo Agostinho, quem, também fala de "existência" e sobre o tempo que antecede e sucede o presente, o que se pode verificar, por exemplo, na seguinte passagem: "Assim, qualquer que seja a natureza deste misterioso pressentimento do futuro, não se pode ver senão o que existe. Ora, o que já existe não é futuro, mas presente." (Confissões: XI, XVIII-24)

Voltemos a Benveniste. Partindo de outro ponto de vista e com a intenção de distinguir o sistema verbal, relativamente ao tempo, a partir de dois planos de enunciação "o tempo da história e o tempo do discurso", Benveniste (1988, p. 260276) analisa aspectos do sistema verbal francês. O "tempo da história" é o que não arrasta consigo os dados da situação de fala e o "tempo do discurso" é o que é mais complexo, porque traz consigo toda a complexidade da enunciação, a situação do sujeito que fala postado em um tempo, espaço e lugar. É fundamentado nisso que Benveniste desmonta a ideia de que a utilização de um presente no lugar de um passado não é uma “irregularidade" e de que o passado simples "está desaparecendo" porque não existe no francês falado. Segundo explica, isso acontece porque há dois sistemas verbais, o da história, desprovido de marcas enunciativas do sujeito falante, cuja forma típica é o aoristo, mas que também conta com o mais-que-perfeito, e o do discurso cujos tempos fundamentais são o presente, o futuro e o perfeito, sendo o imperfeito comum a ambos os sistemas, o da história e o do discurso. Essa teoria leva o linguista a uma afirmação que o faz recorrer a conceitos presentes na teorização de Beauzée, segundo podemos perceber pelas marcas deixadas em seu texto.

Como este espaço não permite fazer-se uma exploração vertical da relação existente entre as ideias dos autores em causa, apresentamos, para comparação e comprovação de nossa hipótese, apenas dois excertos, um de Beauzée (1756) e outro de Benveniste (1988) para mostrar como as ideias de ambos se conectam, embora, vale ressaltar, Benveniste não repita Beauzée, assim como esse não repetiu Santo Agostinho. Benveniste, ao contrário, até evitou citá-lo.

Observemos, primeiro, o texto do iluminista francês:

Il en est sans doute des irrégularités de la formation, comme de celles des tours $\&$ de la construction; ou elles n'en ont que l'apparence, ou elles menent mieux au but de la parole que la régularité même. Nous disons, par exemple, si je le vois, je lui dirai; les Italiens disent, se lo vedrà, glie lo dirò, de même que les 
Latins, quem si videbo, id illi dicam. Selon les idees ordinaires, la langue italienne $\&$ la langue latine, sont en regles; au lieu que la langue françoise autorise une irrégularité, en admettant un présent au lieu d'un futur. Mais si l'on consulte la saine Philosophie, il n'y a dans notre tour ni figure, ni abus; il est naturel \& vrai. Ce que l'on appelle ici un futur, est un présent postérieur, c'est-à-dire, un tems qui marque la simultanéité d'existence avec une époque postérieure au moment même de la parole, \& ce tems dont se servent les Italiens \& les Latins, convient très bien au point de vûe particulier que l'on veut rendre. Ce que l'on nomme un présent, l'est en effet; mais c'est un présent indéfini, qui independant par nature de toute époque, peut s'adapter à toutes les époques, \& conséquemment a une époque postérieure, sans que cet usage puisse être taxe d'irrégularité.

Existem, sem dúvida, irregularidades de formação, como as das torres e da construção; ou eles têm disso somente a aparência, ou pendem mais para o objetivo da fala do que a própria regularidade. Dizemos, por exemplo, si je le vois (se eu o vir), je lui dirai (direi a ele); os italianos dizem, lo vedrà, glie lo dirò, assim como os latinos, quem si videbo, id illi dicam. De acordo com ideias correntes, a língua italiana e a latim têm regras para isso; enquanto a língua francesa autoriza uma irregularidade, admitindo um presente em vez de um futuro. Mas se consultarmos a boa Filosofia, não há, por seu turno, nem figura nem abuso; é [uso] natural e verdadeiro. O que se chama aqui de futuro, é um presente posterior, isto é, um tempo que marca a simultaneidade da existência com um tempo posterior ao momento da fala, e esse tempo de que se servem Italianos e Latinos, convém muito bem ao ponto de vista particular que se deseja explicar. $\mathrm{O}$ que chamamos presente, o é de fato; mas é um presente indefinido, que por sua natureza é independente de qualquer época, pode adaptar-se a todas as épocas e, consequentemente, a uma época posterior, sem que esse uso seja taxado de irregularidade. (BEAUZÉE: 1765, p. 8: 908) Traduzimos e grifamos.

O que é possível ver nesse trecho? Que a interpretação sobre o sistema verbal é completamente diferente, para a época, do que, então, era comum. Primeiro, observa-se que ele admite como legítimo o emprego de uma forma temporal do presente para indicar uma referência ao futuro, interpretada a partir da análise do momento da fala representada no texto (portanto, uma consideração depois denominada enunciativa) e, mais, o reconhecimento da "forma" do presente como não marcada, "indefinida", pois que pode servir para a referência a qualquer tempo. 
Passando a considerar brevemente a interpretação de Benveniste sobre as relações de tempo representadas pelo verbo francês, veremos que as ideias construídas por Beauzée estão nela latentes, ainda que não sejam repetidas, retomadas ou referidas. O texto de Benveniste traz a ideia do "momento do discurso", ou seja a concomitância temporal da fala com o que ela refere, que vem pelo tempo presente, e o "o momento do acontecimento", isto é, a falta de concomitância do tempo da fala com o tempo do que ela refere, uma forma que é a marca do aoristo, tempo típico da história. Afirma ele:

Como o presente, o perfeito pertence ao sistema linguístico do discurso, pois a marca temporal do perfeito é o momento do discurso, enquanto a marca temporal do aoristo é o momento do acontecimento. (Benveniste 1988, p. 270)

Mais adiante, no mesmo texto, Benveniste recorre a um termo de Beauzée, embora em tom de crítica, quando propõe:

$2^{\circ}$ Os tempos compostos têm outra função, distinta da precedente: indicam a anterioridade. Esse termo se presta facilmente à discussão, mas não encontramos outro melhor. Na nossa opinião, a anterioridade se determina sempre e somente em relação ao tempo simples correlativo. (Benveniste 1988, p. 273) Grifamos.

Para exemplificar como anterioridade funciona no sistema relacional, sintático de tempo que defende, Benveniste trata de suas marcas formais, que são duplas: (i) não podem construir-se como formas livres; (ii) devem empregar-se conjuntamente com formas verbais simples de mesmo nível temporal (Id., p. 273). E, em seguida, exemplifica:

anterior de presente: quand il a écrit une lettre (il l'envoie) anterior de imperfeito: quand il avait écri...e (il l'envoyait) anterior de aoristo: quand il a eut écrit... (il l'envoya) anterior de futuro: quand il aura écri... (il l'enverra)

Essa comparação não visa a desqualificar a construção de Benveniste, antes, a mostrar que sua análise não se fez "do nada", mas com base em ideias anteriormente 
Linha D’Água (Online), São Paulo, v. 32, n. 1, p. 1-22, jan.-abril 2019

defendidas e que constituíram uma invenção (a teoria do tempo de Beauzée) e depois, uma inovação. A teoria de Benveniste não é especificamente uma teoria do tempo verbal como a de Beauzée, mesmo porque não tem o mesmo escopo e, também, porque se enquadra em outro sistema de conhecimento, pois não é centrado no campo específico da teoria gramatical, mas na teoria do discurso. Nesse território, a teoria de Benveniste, sem ser uma invenção, é uma inovação.

Auroux (1985,p.292) assinalou a relação existente entre as ideias de Benveniste com as de Beauzée e afirmou:

La noción de tiempo indefinido corresponde, em nuestra interpretación, al caso en que T1 no está presente en la marca de la enunciación. Hay aquí un punto de vista profundo de Beauzée, que conecta con los análisis modernos del valor aorístico (op. cit., 99; ver Benveniste, 1959; estos análisis han sido profundizados en los seminarios de A. Culioli (CULIOLI, 1980 y DESCLÉS, 1980: 46).

A noção de tempo indefinido, segundo nossa interpretação, ao caso em que T1 [tempo do acontecimento] não está presente na marca da enunciação. Há aqui um ponto de vista profundo de Beauzée, que se conecta com as análises modernas do valor do aoristo (op. cit, 99 [Beauzée 1756, artigo Tems de L'Encyclopédie]; Benveniste, 1959; estas análises foram aprofundadas nos seminários de A. Culioli (CULIOLI, 1980 e DESCLÉS, 1980: 46). (Cf. Auroux 1985, p. 292)

Se se perguntar se há uma prova "documental" sobre a relação existente entre os dois pensadores, talvez a resposta não seja fácil. Não obstante isso, não impossível, pois se pode argumentar que, em primeiro lugar, a proximidade dos conceitos e a coincidência terminológica e conceitual (sobre anterioridade, nesse trecho) seja uma prova robusta de que o linguista francês, mesmo fazendo a manifestação de restrição do uso do termo anterioridade, está próximo da teoria do iluminista. Embora haja a utilização do termo e sua carga semântica seja bem próxima em ambas as teorias, não é possível aproximá-las muito, pois o sistema de conhecimento sobre o qual trabalha o linguista é diferente daquele do século XVIII.

Para a língua portuguesa, variedade brasileira, por exemplo, uma aplicação construtiva e produtiva dessa teoria benvenistiana foi realizada com maestria por Fiorin (1996), na obra As astúcias da enunciação, o que comprova a validade 
Linha D'Água (Online), São Paulo, v. 32, n. 1, p. 1-22, jan.-abril 2019

a importância da teoria discursiva das relações de tempo no verbo no contexto da linguística enunciativa. Nessa obra, Fiorin avança em relação à teorização de Benveniste, com proveito para a descrição do português, pela análise da realização de todo sistema verbal em textos literários. O "todo" significa que o autor explora exaustivamente as combinações verbais da língua portuguesa, e não somente as formas simples e compostas que conformam o paradigma verbal constante nos manuais didáticos. O que interessa mais sobre esse trabalho do linguista brasileiro, neste momento, é o fato de ele, diferentemente do que faz Benveniste, ter explorado ao máximo os conceitos de simultaneidade, anterioridade e posterioridade, relacionando-os sempre ao momento de referência e ao momento do acontecimento do ato enunciativo, a fim de extrair os efeitos de sentido que a forma verbal cria nos contextos analisados.

O objetivo de Fiorin (1996), é o de estudar o mecanismo enunciativo da embreagem e da debreagem que implica das categorias da enunciação (pessoa, tempo e espaço). Nesse contexto seu objeto foi o uso invertido (ou trocado) de entes gramaticais: de uma pessoa, por outra (por exemplo, do plural majestático em que a $1^{\text {a }}$ pessoa do plural, nós, é usada pela $1^{\text {a }}$ do singular, eu), de um tempo verbal por outro (por exemplo, do presente pelo futuro em uma frase como "Vou lá amanhã", em vez de "Irei lá amanhã"), de um demonstrativo por outro (por exemplo, de esse por este, em uma frase como "Esse é o livro que lhe dou", em vez de "Este livro é o que lhe dou"). Nesse contexto, o autor trata profundamente das possibilidades da transformação e transbordamento das categorias gramaticais envolvidas no processo de debreagem.

Para tratar do tempo, o fundamento filosófico a que recorre vem de Aristóteles (Física, IV, 10, 218a , 220b) e de Santo Agostinho (Confissões XI) e o linguísticodiscursivo é de Benveniste, pelo capítulo aqui citado, As relações de tempo no verbo francês. Não vemos na obra do linguista brasileiro, assim como não vimos na do francês, porém, nenhuma referência a Beauzée. O ponto de partida de Fiorin (1996, p. 145) para análise do sistema verbal é claro: o momento da enunciação e a adaptação que o verbo sofre por exigência do processo narrativo. Assim, o linguista desenha um o sistema verbal binário, com base na categoria de concomitância (ou seja, identidade do ato com o momento da fala) e sua contraparte não concomitância 
Linha D’Água (Online), São Paulo, v. 32, n. 1, p. 1-22, jan.-abril 2019

(ou seja, descolamento da fala com o momento da fala) e, somente a partir delas, tratar da anterioridade e da posterioridade. Voltemos ao sistema ternário de Beauzée (ver citação anterior neste texto) estruturado sobre o "ato da fala" a partir do qual ele criou seu sistema verbal fundado na simultaneidade, a partir da qual surgem a anterioridade e a posterioridade. Apenas para comprovar o que vimos dizendo, observemos o que explica Fiorin:

(...) ao momento da enunciação, já que é o eixo fundamental de ordenação temporal da língua. Por isso, ao momento da enunciação aplicamos a categoria tipológica concomitância vs. não concomitância (anterioridade vs. posterioridade) e obtemos três momentos de referência: concomitante, anterior e posterior, ao momento da enunciação. Se o momento da referência é concomitante ao momento da enunciação, utilizamos o sistema enunciativo, já que tudo estará referido ao momento da enunciação. (FIORIN :1996, p. 146)

À guisa de conclusão desse ensaio, para mostrar um pouco de como a pesquisa baseada nos pressupostos da História das ideias linguisticas ${ }^{4}$ pode ser realizada, observamos o seguinte: de acordo com o princípio da continuidade do conhecimento, partimos do pressuposto que a mudança (portanto a descontinuidade natural ao progresso da ciência) do conhecimento pressupõe um caminho percorrido no curso do tempo. $\mathrm{O}$ objeto, portanto, que se nos apresenta tem uma história, e devemos recuar até onde for possível para entender as transformações pelas quais aquele objeto selecionado para a investigação tem aquela configuração e não outra.

Aqui fizemos um breve estudo sobre a descrição do tempo verbal. Para iniciar o trabalho lembramos que, sobre o estudo do tempo, como categoria intelectual, conhecem-se as formulações originárias da filosofia e da física; já, sobre os estudos do tempo como categoria gramatical, conhecem-se os trabalhos da gramática clássica, greco-latina, e de seus desdobramentos que, necessariamente, retomam os saberes formulados nas duas áreas antes referidas. Sabendo que, no séculos XVII e XVIII a teorização gramatical passou por uma renovação, e que um de seus representantes, Nicholas Beauzée tornou-se conhecido, também, por seu estudo sobre o sistema verbal, proposição diferente do que se fazia no âmbito da gramática,

4 Outros exemplos podem ser vistos em (LEITE;PELFRÊNE: 2018 e 2019.) 
Linha D'Água (Online), São Paulo, v. 32, n. 1, p. 1-22, jan.-abril 2019

por valer-se de conhecimentos anteriores, principalmente daquele formulado no âmbito da física, examinamos uma proposta mais contemporânea, do século XX, 1959, de Émile Benveniste.

O sistema verbal de Beauzée, inovador, teve desdobramentos, mas, por estar fincado em bases lógico-filosóficas e configurar-se como racionalista e metafísico foi ultrapassado pela linguística positivista dos séculos XIX e XX. As preocupações mais discursivas e menos linguístico-formalistas, contudo, colocaram um linguista, Émile Benveniste, de volta à trilha da investigação mais filosófica e menos formalista e, portanto, ele reconstruiu esse conhecimento, inovando outra vez, fazendo o conhecimento relacionado à questão do tempo progredir. A comprovação disso não é, exatamente, o capítulo do linguista francês, mas a obra do brasileiro que faz uma exploração exaustiva do tempo, no contexto de outra teoria, a da enunciação. Um outro sistema, portanto.

\section{Os trabalhos historiográficos deste número da Linha D'Água}

Os artigos deste número temático trazem, de modo mais ou menos explícito, quanto à exposição teórica de seus fundamentos, um trabalho de análise de ideias linguísticas, relacionando-as, ou não, a uma cronologia ou a uma teoria. São pesquisas, portanto, que se enquadram no campo das duas principais teorias modernas para o desenvolvimento de pesquisas de caráter historiográfico no domínio das ciências da linguagem, a História das Ideias Linguísticas, sobre a qual discorremos um pouco aqui, e a Historiografia da Linguística. As duas teorias têm pontos coincidentes e divergentes, embora não sejam inconciliáveis, tanto que muitos pesquisadores, mesmo cientes das diferenças, se beneficiam de pontos positivos de uma e de outra, para resolverem alguns problemas surgidos durante a análise de seus objetos. $\mathrm{O}$ ponto de ligação das duas teorias, e o que une todos os que se dedicam à exegese histórica de fatos inerentes às ciências da linguagem, é o objetivo de construir uma "história argumentativa", por meio de um discurso mais demonstrativo e menos narrativo, ou "apresentativo", que seja aquele capaz de comprovar a relação existente entre o dado analisado (o efeito) e suas causas, por intermédio de provas documentais, ou 
Linha D'Água (Online), São Paulo, v. 32, n. 1, p. 1-22, jan.-abril 2019

pela comprovação de nexo entre ideias. Algumas questões relativas à semelhança e diferença entre essas duas teorias foram estudadas em Leite (2019).

Como o trabalho do historiador exige que tenha contato direto com textos antigos que constituem a "documentação", seu material de trabalho,é imprescindível que se construam, cada vez mais, eficientes bancos de dados, de que constem obras originais e completas para servirem à análise e interpretação de teorias e de ideias. Por tal razão, a equipe de pesquisadores do Laboratoire d'Histoire et des Théories Linguistiques, coordenada pelo professor Bernard Colombat (CNRS | Univ. Paris 7) criou o projeto Corpus de Textes Linguistiques Fondamentaux (CTLF), cujos resultados estão disponíveis no endereço http://ctlf.ens-lyon.fr/default. $\mathrm{htm}$. O CTLF é um portal que inclui cinco tipos de informações sobre textos metalinguísticos: fichas descritivas (mais de 700 até o momento), bibliografia com mais de 4000 mil referências, textos em pdf (que acompanham as fichas descritivas), e textos digitalizados que permitem pesquisa por palavra (mais de 300 obras) e inúmeros artigos científicos. $\mathrm{O}$ acesso ao site é livre e gratuito a todos os interessados em textos metalinguísticos, de diversos gêneros (gramáticas, ortografias, dicionários, observações sobre uso e norma etc.), e de várias línguas, tais como francês, inglês, português e outras, por meio de instrumentos linguísticos produzidos em diversos momentos da história.

Vale ressaltar que no CTLF cada página digitalizada em modo texto é acompanhada da imagem de seu original, em formato pdf, para que o leitor possa, em caso de dúvida, consultar o original. As fichas descritivas das gramáticas encontram-se no site CTLF, na aba verde, denominada em francês Notices, e os textos completos e pesquisáveis encontram-se na aba amarela, denominada Textes. Nesse site já estão disponíveis gramáticas brasileiras e portuguesas, em edição pesquisável, prontas para serem utilizadas pelos pesquisadores dedicados à história das ideias e das teorias linguísticas (ou da linguística).

As gramáticas portuguesas foram preparadas pelo professor Carlos Assunção, da Universidade Trás-os-Montes Alto Douro (UTAD) e sua equipe, formada por investigadores do Centro de Estudos em Letras (CEL). As brasileiras, por sua vez, foram preparadas pela Professora Marli Quadros Leite, da Universidade de São 
Linha D’Água (Online), São Paulo, v. 32, n. 1, p. 1-22, jan.-abril 2019

Paulo, e sua equipe, do GT | CNPq Gramática: história, descrição e discurso. ${ }^{5} \mathrm{O}$ trabalho técnico com o corpus desenvolveu-se sob a supervisão do professor Bernard Colombat e sua equipe técnica e, também, sob orientação do professor Arnaud Pelfrêne, quem trabalha diretamente com a preparação do material a ser submetido ao pesquisador para a realização do tratamento textual e linguístico-filológico sobre o material. Esse é um trabalho penoso, mas de grande importância para o desenvolvimento científico da área, e por sua relevância social, por democratizar o acesso de pesquisadores de todos os lugares do planeta, interessados nesses dados, a materiais raros, ou de difícil alcance. É um grande esforço em prol da comunidade científica interessada na pesquisa histórica do domínio das ciências da linguagem. $\mathrm{N}$ este texto apresentamos a lista das gramáticas (anexa) portuguesas e brasileiras disponíveis no site CTLF, antes mencionado.

Ainda tratando das características desse número da Linha D'Água, é relevante acentuar que ele cumpre uma exigência importante no contexto da prática acadêmica: a internacionalização. A chamada atraiu pesquisadores brasileiros e estrangeiros identificados com a proposta formulada para este número. Submeteram artigos pesquisadores estrangeiros da Europa (França, Portugal e Espanha) e da América do Sul (Argentina). Quanto aos brasileiros, é também importante chamar a atenção para o fato de haver artigos de pesquisadores oriundos de universidades localizadas em diferentes estados da federação (Rio de Janeiro, Tocantins, Paraná e São Paulo). Passemos a ver um pouco da coleção de artigos aqui publicados.

Jacqueline Léon, professora do Centre National de la Recherche Cientifique (CNRS) e Université Paris Diderot (Paris - França), é autora do artigo As origens britânicas da etnografia da comunicação e da análise da conversação. Bronislaw Malinowski e John Rupert Firth, no qual examina os fundamentos britânicos da etnografia da comunicação e da análise da conversação, buscando investigar as ideias a respeito de variação, repertório, noções conversacionais de turno de fala e sequência de ações de B. Malinowski e de J.R. Firth em trabalhos de 1930, para mostrar como Firth estabeleceu a categoria de contexto de situação nos anos 1950.

5 Parte do trabalho com as gramáticas brasileiras resultou de um projeto de pesquisa desenvolvido pela Professora Marli Quadros Leite, em Paris, no ano acadêmico de 2017-2018, por meio de uma bolsa CAPES. 
Carlos Assunção e Carla Araújo, o primeiro da Universidade de Trás-os-Montes e Alto Douro/UTAD, a segunda do Instituto Politécnico de Bragança/IPB, ambos de Portugal, escreveram o texto Entries on the History of Corpus Linguistics (Subsídios para a linguística de corpus), em que se propõem a discutir pelo fundamento da Linguística de corpus, o empirismo, sua relação com o racionalismo, por meio de uma pesquisa que perpassa longo período histórico, "da tradição à modernidade", a fim de examinar o fundamento de cada estágio em que o corpus é empregado por diversas teorias, revelando, assim, o progresso alcançado na área.

Emilianao Batista, da Universidad de Buenos Aires-CONICET (Argentina), é autor de $A$ falácia do historiador whig. O caso de Noam Chomsky e sua Linguística cartesiana (1966), em que trabalha com duplo objetivo, de um lado analisando o “modo de historicização" (Auroux, 2006) da obra Cartesian Linguistics (1966), de Noam Chomsky e, de outro, recuperando o contexto em que a obra foi publicada afim de identificar a emergencia e consolidação dos fundamentos epistemológicos da historiografia da linguística. O foco do autor é mostrar que Chomsky incorreu na "falácia do historiador "wig", ou seja, praticou um anacronismo ao trazer a filosofia cartesiana para validar uma teoria do presente.

Ricardo Cavaliere, professor da Universidade Federal Fluminese (Niterói - Rio de Janeiro), no artigo O nome da língua no Brasil Oitocentista, faz um passeio por textos avulsos, principalmente jornalísticos, mas também apoiado em dicionários, gramáticas e outros textos metalinguísticos, para comentar e analisar as primeiras referências à denominação do português falado no Brasil. A conclusão do autor é a de que no século XIX a referência à língua tinha duas bases, uma laica e outra científica.

Rogelio Ponce de León Romeu, professor da Universidade do Porto (Portugal), submeteu o texto Os verbos impessoais na gramaticografia portuguesa setecentista, com o propósito de examinar as diferentes abordagens feitas pelos gramáticos acerca dos verbos impessoais portugueses, latinos e espanhóis. $\mathrm{O}$ autor visa a encontrar as fontes que fundamentam o tratamento teórico, convergente ou divergente, desse tipo de verbo estabelecendo entre elas possível relação.

José Edicarlos de Aquino, da Universidade Federal do Tocantins (Porto Nacional - Tocantins) trouxe à luz o artigo A polêmica entre Júlio Ribeiro e Alberto 
Linha D'Água (Online), São Paulo, v. 32, n. 1, p. 1-22, jan.-abril 2019

Sales: uma análise do debate sobre o modelo ideal de organização das ciências e o emprego apropriado de referências teóricas na produção linguística no Brasil no século XIX, em que analisa uma acusação de plágio das ideias de Augusto Compte pelo gramático Júlio Ribeiro,feita por Alberto Sales (1857-1904), paulista,jornalista e deputado federal orador republicano, autor de Catecismo republicano (1885). O Objetivo de Aquino é, mais do que tratar do plágio, ressaltar a "a ressignificação das referências teóricas por parte de Júlio Ribeiro”, para mostrar que Júlio Ribeiro, ainda assim, constrói trabalho original.

Ronaldo Batista, professor da Universidade Presbiteriana Mackenzie (São Paulo - SP), escreveu o artigo Ensino de lingua, livros didáticos e história: relaçôes vistas pela Historiografia da Linguística, em que analisa a produção e circulação de livros didáticos no Brasil. O autor trabalha com um estudo de caso, pela análise do livro Leitura de mundo, 5a série (1998), a fim de mostrar como esse tipo de obra, não obstante a sua contemporaneidade, traz em si a história do conhecimento, inserindo-o na continuidade dos saberes, pois, diz o autor "A configuração discursiva (histórica, consequentemente) de um livro didático insere este material ativo do processo de ensino-aprendizagem em uma tradição de conhecimento".

Mairus Prete,é professor do Instituto Federal do Paraná (Jacarezinho, Paraná) é autor do artigo Influência da gramática fllosófica no conceito de verbo em gramáticas brasileiras, em que analisa o conceito de gramática em obras dos séculos XIX e XX, com o intuito de mostrar que traços da concepção de verbo, oriunda de gramáticas filosóficas de referência, como a de Jerônimo Soares Barbosa (1822), são ainda presentes em obras que avançam o século XX até, de certo modo, o século XXI.

Eustaquio Sánchez Salor, professor da Universidad de Extremadura, (Cáceres - España), é o autor do artigo intitulado La Méthode latine de Du Marsais: Críticas y apologías contemporáneas. Nesse texto, o autor examina a polêmica travada, pelos jornais, entre o filósofo e gramático francês César Chesneau Du Marsais e interlocutores contrários a seu método de ensino do latim, intitulada La Méthode latine. É também objeto de análise a proposta de Du Marsais sobre o ensino do latim, apresentada como "um método racional para aprender a língua latina". O autor também considera no texto as manifestações favoráveis ao método de ensino de Du Marsais, feitas por seguidores seus, os quais, forma editores de sua obra. As 
Linha D'Água (Online), São Paulo, v. 32, n. 1, p. 1-22, jan.-abril 2019

respostas dadas por próprio Du Marsais em defesa de suas ideias são, evidentemente, trazidas à lume, para exame, no confronto e contraste com as ideias dos opositores.

Este é o conjunto de textos que Linha d'Água oferece ao leitor, na esperança de que ele renda reflexões, suscite novos estudos e provoque o surgimento de novas pesquisas. Assim a roda da ciência continua sua marcha.

A publicação deste número contou com o auxílio do Programa de Apoio às Publicações Científicas Periódicas da Universidade de São Paulo/SIBi, a quem agradecemos por permitir a manutenção de Linha d'Água, que a partir de 2018 foi indexada na Web of Science, base de dados de citações científicas do Institute for Scientific Information, mantido pela Clarivate Analytics, nas áreas de Ciências Sociais, Artes e Humanidades.

O processo de submissão e seleção dos artigos conta com pareceristas do Conselho editorial e ad hoc, procedimento que torna este número de alta qualidade. Linha d'Água mantém seu espaço aberto para publicações ligadas à língua portuguesa, aos estudos linguístico-discursivos e sua relação com o ensino, mantendo um diálogo constante com os estudos desenvolvidos no Brasil e no exterior.

Com esse número da revista e do ano anterior, o Conselho Editorial busca a internacionalização do periódico com artigos de autores de diferentes universidades brasileiras e estrangeiras, procurando responder às exigências da Web of Science e também da Universidade de São Paulo.

\section{Referências}

AUROUX, S. La teoría de los tiempos en la gramática general francesa (Beauzée y Destutt de Tracy) E.L.U.A. 3, 1985-1986, págs. 287-312.

AUROUX, S. Une nouvelle histoire de la grammaire française. In : Colombat, B.; Fournier, J-M; Raby. Vers une histoire générale de la grammaire française. Matériaux et perspectives. Paris: Champion, 2012, p. 27-44.

AGOSTINHO, Santo. As Confissões. In: Os Pensadores: Santo Agostinho. Trad. J. Oliveira Santos e A. Ambrósio de Pina São Paulo: Abril Cultural, 1978. 
Linha D'Água (Online), São Paulo, v. 32, n. 1, p. 1-22, jan.-abril 2019

BEAUZÉE, Nicholas. Articles de l'Encyclopedie. Tems. Compilation établie à partir de l'édition numérisée de l'ARTFL, 1765. http://obvil.sorbonne-universite.site/corpus/critique/html/ beauzee_encyclopedie.html\#index

BENVENISTE, E. As relações de tempo no verbo francês. In: Problemas de linguistica geral. Trad. Maria da Glória Novak e Maria Luiza Neri. Campinas, São Paulo: Pontes, 1988, p. 260276. [1959]

CHEVALIER, J-C. Pour saluer Sylvaim Auroux (Postface). In: Archaimbault, S; Fournier, J-M; Raby, V. Penser l'bistoire des savoirs linguistiques. Hommage à Sylvain Auroux. Lyon : ENS, 2014, p. 679-687.

COLOMBAT, B.; FOURNIER, J-M; PUECH, C. Uma história das ideias linguísticas. Trad. Marli Quadros Leite e Jacqueline Léon. São Paulo: Contexto, 2017.

FIORIN, J.L. AS astúcias da enunciação: as categorias de pessoa, espaço e tempo. São Paulo: Ática, 1996.

FISHER, S. D'um corse à l'autre : quelques étapes d'un parcours se Sylvain Auroux. In : Archaimbault, S.; Fournier, J-M; Raby, V. Penser l'histoire des savoirs linguistiques. Hommage à Sylvain Auroux. Lyon: ENS, 2014, p. 219-227.

LEITE, M. Q. Historiografia da linguística e História das Ideias linguísticas: aproximação e distanciamente. In: Batista, R. (Org.). São Paulo: Contexto, 2019, p. 139-181.

LEITE, M. Q.; PELFRÊNE, A (Orgs). Compendio da Grammatica Philosophica da Lingua Portugueza: Padre Antonio da Costa Duarte. São Paulo: @FFLCH. Disponível em: http://www.livrosabertos.sibi.usp.br/portaldelivrosUSP/catalog/book/218

LEITE, M. Q.; PELFRÊNE, A (Orgs). Breve Compendio de Grammatica Portugueza: organizado em forma systematica, com adaptação a capacidade dos alumnos Frei Joaquim do Amor Divino Caneca. São Paulo: @FFLCH. Disponível em: http://www.livrosabertos.sibi.usp.br/portaldelivrosUSP/ catalog/book/304 
Linha D'Água (Online), São Paulo, v. 32, n. 1, p. 1-22, jan.-abril 2019

\section{Anexo: Obras em português no CTLF}

\begin{tabular}{|c|c|c|c|}
\hline Autor & Título & Ano ['] & CTLF \\
\hline Oliveira, Fernão de & Grammatica da lingoagem portuguesa & 1536 [id.] & 3301 \\
\hline Barros, João de & Grammatica da lingua portuguesa & 1540 [id.] & 3302 \\
\hline Roboredo, Amaro de & Methodo grammatical & 1619 [id.] & 3303 \\
\hline Argote, Jerónimo & Regras da lingua portugueza, espelho da lingua latina & 1721 [id.] & 3304 \\
\hline Lobato, António & Arte da grammatica da lingua portugueza & 1770 [id.] & 3305 \\
\hline Bacelar, Bernardo & Grammatica philosophica, e orthographia racional & 1783 [id.] & 3306 \\
\hline Casimiro, João & Methodo grammatical resumido & 1792 [id.] & 3308 \\
\hline Figueiredo, Pedro & Arte da grammatica portugueza & $1799[1837]$ & 3309 \\
\hline Fonseca, Pedro & Rudimentos da grammatica portugueza & 1799 [id.] & 3310 \\
\hline Sousa, Manuel & Gramatica portugueza & 1804 [id.] & 3311 \\
\hline Silva, António & Epitome & 1806 [id.] & 3313 \\
\hline Melo, João & Grammatica filosofica & 1818 [id.] & 3315 \\
\hline Ferreira, Francisco & Elementos de grammatica portugueza & 1819 [id.] & 3316 \\
\hline Barbosa, Jerónimo & Grammatica philosophica & 1822 [id.] & 3317 \\
\hline Oliveira, Bento & Nova grammatica portugueza & $1862[1864]$ & 3319 \\
\hline Aulete, Francisco & Gramática Nacional & $1864[1874]$ & 3320 \\
\hline Azevedo, Domingos & Grammatica nacional & 1880 [id.] & 3322 \\
\hline Coelho, Francisco & Noçoes elementares da grammatica portugueza & 1891 [id.] & 3324 \\
\hline Andrade, Jerónimo & Primeiros elementos de grammatica portugueza & $1843[1865]$ & 3328 \\
\hline Duarte, Antonio & Compendio da grammatica da lingua portuguesa & $1829[1877]$ & 3373 \\
\hline Condurú, Filippe & Grammatica elementar da lingua portugueza & $1850[1888]$ & 3375 \\
\hline Villeroy, Frederico & Compendio da grammatica portugueza & 1870 [id.] & 3376 \\
\hline Reis, Francisco & Grammatica portugueza & $1866[1871]$ & 3377 \\
\hline Rabello, Laurindo & Compêndio de grammatica da lingua portugueza & $1867[1872]$ & 3378 \\
\hline Bandeira, Adélia & Grammatica portugueza practica & $1897[1929]$ & 3379 \\
\hline Caneca, Frei & Breve Compendio de Grammatica Portugueza & 1876 [id.] & 3380 \\
\hline Caetano, Baptista & Rascunhos sobre a grammatica da lingua portugueza & 1881 [id.] & 3381 \\
\hline Grivet, Charles & Nova Grammatica Analytica da Lingua Portugueza & 1881 [id.] & 3382 \\
\hline Ribeiro, Júlio & Grammatica portugueza & $1881[1885]$ & 3383 \\
\hline Silva Jr., M. Pacheco & Grammatica da lingua portugueza & $1887[1894]$ & 3384 \\
\hline
\end{tabular}

[continua] 
Linha D'Água (Online), São Paulo, v. 32, n. 1, p. 1-22, jan.-abril 2019

[continuação]

\begin{tabular}{cccc}
\hline Autor & Título & Ano [1] & CTLF \\
\hline Silva Jr., M. Pacheco & Noções de grammatica portugueza & 1887 [id.] & 3386 \\
\hline Pereira, Eduardo & Gramática expositiva & $1907[1945]$ & 3387 \\
Ali, Manuel Said & Grammatica secundaria da lingua portugueza & $1923[1927]$ & 3390 \\
\hline Ali, Manuel Said & Grammatica elementar da lingua portugueza & $1924[1966]$ & 3391 \\
Ali, Manuel Said & Grammatica histórica da lingua portugueza & $1923[1931]$ & 3392 \\
\hline Maciel, Maximino & Grammatica Descriptiva & $1887[1914]$ & 3393 \\
\hline Lima, Carlos & Gramática normativa da lingua portuguêsa & $1957[\mathrm{id}]$. & 3394
\end{tabular}

1 Indica-se entre colchetes o ano da primeira edição da gramática e a sua direita o número da obra no site CTLF. 